\title{
Tuberculosis in an inflammatory bowel disease cohort from South Africa
}

\author{
E Deetlefs, D Epstein, G A Watermeyer, R M Seggie, S R Thomson
}

Background. Potent immunosuppressive therapy is standard treatment for inflammatory bowel disease (IBD) but carries a risk of reactivating latent tuberculosis (TB). No data exist on the burden of TB in South African patients with IBD.

Objective. To evaluate the burden of TB in IBD patients attending a large tertiary IBD clinic.

Methods. Data pertaining to patients attending the Groote Schuur Hospital IBD clinic were retrospectively analysed. Data were extracted from an existing IBD database, patient notes, the National Health Laboratory Services database and chest X-ray analysis.

Results. Of 614 patients, 72 (11.7\%) were diagnosed with TB; 40 (55.6\%) developed TB prior to the diagnosis of IBD. On regression analysis, coloured IBD patients were at increased risk for TB development ( $p=0.004$, odds ratio (OR) $3.57,95 \%$ confidence interval (CI) $1.49-8.56$ ), as were patients with extensive Crohn's disease (CD) compared with those with less extensive disease $(p=0.001$, OR $2.84,95 \%$ CI 1.27 - 6.33). No other risk factors, including the use of immunosuppressive agents, were identified for the development of TB.

Conclusions. Of over 600 patients, 12\% had TB either before or after IBD diagnosis. The high rate of previous TB and positive association with ethnicity probably reflect the high burden of TB in a socio-economically disadvantaged community. We recommend that IBD patients should be screened actively and monitored for TB when immunosuppressive medications are used.

S Afr Med J 2012;102(10):802-804. DOI:10.7196/SAMJ.5609
The incidence of tuberculosis (TB) in South Africa (SA) - estimated to be the second highest incidence in the world according to the World Health Organization (WHO) - has reached epidemic proportions. ${ }^{1}$ The Western Cape has a TB incidence of 1 053/100 000 per annum (M Poolman, personal communication). Inflammatory bowel disease (IBD) is increasing in many developing countries. ${ }^{2,3}$ In Cape Town, a growing cohort of IBD patients are treated at the Groote Schuur Hospital (GSH) IBD clinic.

Standard care includes treatment with immunosuppressive therapy suchascorticosteroids, thiopurines(azathioprineand6-mercaptopurine) and tumour necrosis factor-alpha (TNFa)-antagonists. ${ }^{4,5,6}$ The use of these drugs, alone and in combination, is associated with reactivation of latent TB. ${ }^{7}$ Increasingly, immunomodulators and TNF $\alpha$-antagonists are used earlier and more aggressively to modify the natural course of IBD. ${ }^{8}$ Treatment protocols are based on experience in developed countries with a low TB prevalence, ${ }^{1}$ good healthcare infrastructure and patients knowledgeable about treatment side-effects. The high TB incidence in the Western Cape and the increasing emergence of IBD in SA and other developing countries pose management challenges. Treating IBD according to internationally accepted protocols may not be appropriate in developing countries.

Recent data on TB incidence in IBD patients in the developing world are lacking. In Spain up to $12.5 \%$ of IBD patients have latent TB

Division of Gastroenterology, Department of Medicine, University of Cape Town and Groote Schuur Hospital, Cape Town

E Deetlefs, MB ChB, FCP (SA), Cert Gastroenterology (SA)

D Epstein, MB ChB, DCH, FCP (SA), Cert Gastroenterology (SA)

G A Watermeyer, MB ChB, FCP (SA), Cert Gastroenterology (SA)

$S$ R Thomson, ChM, FRCS (Eng \& Ed)

Department of Radiology, University of Cape Town and Groote Schuur Hospital, Cape Town

R M Seggie, MB ChB, FFRad (D) (SA)

Corresponding author: E Deetlefs (eduan@gidoc.co.za) according to tuberculin skin testing (TST) results. ${ }^{9}$ In comparison, a study from a high TB burden area in SA found that among otherwise healthy adolescents about $50 \%$ had a TST $>5 \mathrm{~mm}$ or a positive Quanti-FERON ${ }^{\circledR}$-TB Gold In-Tube (QFT) assay. ${ }^{10}$ Data on TB in IBD patients in SA would be valuable for the development of appropriate treatment guidelines; we therefore studied the burden of TB in our cohort of IBD patients.

\section{Methods}

We performed a retrospective analysis of the cohort of the GSH IBD clinic from 2002 to 2009. Baseline characteristics and $\mathrm{TB}$ data were obtained from an existing IBD database and from the National Health Laboratory Service database. Clinical records and chest X-rays were reviewed. Criteria for determining TB-positive patients included: (i) microbiological confirmation (smear positive for acid-fast bacilli or TB culture positive); (ii) histology consistent with TB; (iii) chest X-ray diagnosis of latent $\mathrm{TB}$ according to Centers for Disease Control and Prevention guidelines; ${ }^{11}$ and (iv) a clinical record history of treatment with anti-TB chemotherapy and associated resolution of symptoms suggestive of TB. Patients with confirmed IBD and a history of empiric treatment for intestinal $\mathrm{TB}$ without objective evidence of $\mathrm{TB}$ were not considered to be TB-positive. The use of immunosuppressive therapy was defined as any history of exposure to azathioprine, 6-mercaptopurine, methotrexate, infliximab and adalimumab. Data were not available on the use of corticosteroids.

Data were analysed to identify possible risk factors for TB development in IBD. Statistical analyses were performed with STATA software (Release 11). Continuous variables were expressed as medians and interquartile ranges (IQRs) (nonGaussian distribution). Mann-Whitney tests were used to assess continuous variables, and chi-square or Fisher's exact tests were used for categorical variables. Univariate analysis was performed initially for each variable. Multivariate logistic regression models were used for variables differing between the TB-positive versus negative groups with a significance level of $p<0.1$ and other possible confounders. A $p$-value $\leq 0.05$ was considered to be significant. 


\section{Results}

Database entries were available for 614 of the 1388 IBD patients who attended the clinic since its inception (Table 1), including 63\% women, $66 \%$ coloured, $25 \%$ white, $5 \%$ black, and $4 \%$ Asian patients. The median age at IBD diagnosis was 32 years (IQR 24 - 43). Fiftythree per cent of patients had Crohn's disease (CD), $44 \%$ ulcerative colitis (UC) and 3\% unclassified IBD (IBD-U). Seventy-seven per cent of patients with $\mathrm{CD}$ and $40 \%$ with UC were current or previous smokers. Only $25 \%$ received immunosuppressive therapy during management. The current practice is to test for HIV at diagnosis of IBD, but this was not standard policy until recently; the HIV status of the cohort was therefore not determined.

Seventy-two (11.7\%) patients were diagnosed with TB based on a history of treatment and clinical recovery in 26 (36.1\%), microbiological evidence in $17(23.6 \%)$, culture positivity for

\begin{tabular}{|c|c|}
\hline & $\begin{array}{l}\text { No. of patients } \\
n(\%)^{*}\end{array}$ \\
\hline Age at diagnosis of IBD, years (IQR) & $32(24-43)$ \\
\hline \multicolumn{2}{|l|}{ Gender $(n=614)$} \\
\hline Female & $387(63)$ \\
\hline Male & $227(37)$ \\
\hline \multicolumn{2}{|l|}{ Race $(n=597)$} \\
\hline Coloured & $394(68)$ \\
\hline White & $148(25)$ \\
\hline Black & $31(5)$ \\
\hline Asian & $24(4)$ \\
\hline \multicolumn{2}{|l|}{ IBD subtype $(n=614)$} \\
\hline $\mathrm{CD}$ & $326(53)$ \\
\hline UC & $269(44)$ \\
\hline IBD-U & $18(3)$ \\
\hline Microscopic colitis & $1(0.2)$ \\
\hline \multicolumn{2}{|l|}{ Extent of disease } \\
\hline \multicolumn{2}{|l|}{$\mathrm{CD}(n=315)$} \\
\hline Ileits & $128(41)$ \\
\hline Colitis & $73(23)$ \\
\hline Ileocolitis & $114(36)$ \\
\hline \multicolumn{2}{|l|}{$\mathrm{UC}(n=253)$} \\
\hline Proctitis & $38(15)$ \\
\hline Left-sided & $94(37)$ \\
\hline Extensive & $121(48)$ \\
\hline \multicolumn{2}{|l|}{ Smoking } \\
\hline \multicolumn{2}{|l|}{ CD and UC $(n=559)$} \\
\hline Never & $220(39)$ \\
\hline Smoker (current or previous) & $339(61)$ \\
\hline \multicolumn{2}{|l|}{$\mathrm{CD}(n=303)$} \\
\hline Never & $71(23)$ \\
\hline Smoker (current or previous) & $232(77)$ \\
\hline \multicolumn{2}{|l|}{ UC $(n=239)$} \\
\hline Never & $144(60)$ \\
\hline Smoker (current or previous) & $95(40)$ \\
\hline \multicolumn{2}{|l|}{ Immunosuppression ( $n=548)$} \\
\hline No & $410(75)$ \\
\hline Any $^{\dagger}$ & $138(25)$ \\
\hline \multicolumn{2}{|c|}{$\begin{array}{l}\text { IBD }=\text { inflammatory bowel disease; } C D=\text { Crohn's disease; } U C=\text { ulcerative colitis; } I B D-U= \\
\text { inflammatory bowel disease unclassified. }\end{array}$} \\
\hline \multicolumn{2}{|c|}{ "Rounded to nearest whole number. } \\
\hline Azathioprine, 6-mercaptopurine, methotrexate an & \\
\hline
\end{tabular}

Mycobacterium TB in 10, a smear positive for acid-fast bacilli in 7 , and chest X-ray changes in 16 (22.2\%). Eleven (15.3\%) patients had a history of TB treatment and chest X-ray changes consistent with $\mathrm{TB}$, while $2(2.8 \%)$ had histological changes suggestive of TB.

In IBD patients diagnosed with TB, 40 (55.6\%) developed TB before IBD diagnosis, 30 (41.7\%) developed TB after IBD diagnosis and $2(2.7 \%)$ acquired TB before and after IBD diagnosis. Sixtyeight (94.4\%) of the TB cases were of pulmonary origin, 2 of TB lymphadenitis, 1 of pleural TB and 1 of terminal ileal TB.

Twelve patients (16.7\%) had a history of immunosuppressive therapy; 7 (9.7\%) were exposed within the 6 months before TB diagnosis; 6 received azathioprine and 1 received infliximab.

On univariate analysis, patients with a history of TB were significantly more likely to be coloured ( $p=0.001$, odds ratio (OR) $2.8,95 \%$ confidence interval (CI) $1.46-5.38$ ), smokers $(p=0.03$, OR $1.85,95 \%$ CI $1.04-3.29$ ) and to have ileocolitis as opposed to isolated small-bowel or colonic involvement ( $p=0.007$, OR $2.42,95 \%$ CI 1.24 4.71). There were no statistical differences between the TB-positive and negative groups regarding age at diagnosis, gender, IBD subtype, or immunosuppression (Table 2). On multivariate analysis, only coloured race ( $p=0.004$, OR 3.57, 95\% CI 1.49 - 8.56) and ileocolitis $(p=0.001$, OR $2.84,95 \%$ CI $1.27-6.33)$ were significantly associated with TB.

\section{Discussion}

We report the first study of TB burden in an IBD population from a developing country. In more than 600 IBD patients, 12\% had TB. In less than half of cases, TB was contracted after IBD diagnosis. Although disturbing, these figures represent Cape Town's $\mathrm{TB}$ incidence, which is one of the highest in the world; the incidence of latent TB is greater than $50 \%$ in high-burden areas. ${ }^{1,7}$

Coloured patients with IBD were over 3 times more likely to develop $\mathrm{TB}$, while white patients with IBD seemed to be relatively protected. This might have been attributed to socio-economic differences, but other causes, including genetic predisposition, need to be investigated. The study was not designed to account for this discrepancy. Furthermore, the traditionally socio-economically disadvantaged black cohort was not at increased risk of TB. It must be noted, however, that this cohort was small. This is a single-centre study; referral bias and the context of the Western Cape racial demographics must be considered.

In patients with $\mathrm{CD}$, extensive intestinal involvement - as opposed to isolated colitis or ileitis - was associated with an increased risk of TB. This is consistent with studies demonstrating that extensive CD is associated with poor outcomes. ${ }^{12}$

Although statistical significance was lost on multivariate analysis patients with a history of smoking were at slightly increased risk of developing TB ( $p=0.22$, OR $1.48,95 \%$ CI 0.79 - 2.79). These findings are compatible with smoking being a risk factor for acquiring TB. ${ }^{13}$

Although immunosuppressive therapy was not identified as a risk factor for the development of $\mathrm{TB}$, there are several points to consider. The sample size was relatively small, and we could not account for steroid use, owing to the retrospective nature of the study. Corticosteroids pose a major risk of TB reactivation - in some studies, exceeding the risk posed by other immunosuppressives. ${ }^{14,15}$ In our unit, access to TNF $\alpha$-antagonists has been limited due to cost constraints; our data do not reflect their increasing use.

The majority of TB cases that developed after IBD diagnosis were pulmonary in origin. This is not the usual presentation for immunosuppressive-associated reactivation of $\mathrm{TB}$, which is typically extrapulmonary and disseminated. ${ }^{16} \mathrm{~A}$ possible explanation is that most of the TB cases represented incidental TB and not reactivation 


\section{RESEARCH}

Table 2. Univariate analysis of TB-positive and -negative groups

\begin{tabular}{|c|c|c|c|c|}
\hline & $\begin{array}{l}\text { TB-positive }(N=72) \\
(n)\end{array}$ & $\begin{array}{l}\text { TB-negative }(N=542) \\
(n)\end{array}$ & $\begin{array}{l}\text { Crude OR } \\
\text { (CI 95\%) }\end{array}$ & $p$-value \\
\hline Age at IBD diagnosis (years) & 34.5 (IQR 23 - 48) & $32(\mathrm{IQR} 24-43)$ & & 0.370 \\
\hline Gender & & & & 0.160 \\
\hline Male & 32 & 195 & $0.70(0.43-1.16)$ & \\
\hline Female & 40 & 347 & & \\
\hline \multicolumn{5}{|l|}{ Race } \\
\hline Coloured & $59 / 394$ & $335 / 394$ & $2.8(1.46-5.38)$ & 0.001 \\
\hline White & $7 / 148$ & $141 / 148$ & $0.3(0.13-0.67)$ & 0.002 \\
\hline Black & $3 / 31$ & $28 / 31$ & $0.79(0.23-2.65)$ & 0.700 \\
\hline Asian & $2 / 24$ & $22 / 24$ & $0.66(0.15-2.9)$ & 0.580 \\
\hline \multicolumn{5}{|l|}{ IBD subtype } \\
\hline $\mathrm{CD}$ & $43 / 326$ & $283 / 326$ & $1.36(0.82-2.24)$ & 0.230 \\
\hline $\mathrm{UC}$ & $28 / 269$ & $241 / 269$ & $0.78(0.48-1.32)$ & 0.370 \\
\hline IBD-U & $1 / 18$ & $17 / 18$ & $0.44(0.06-3.33)$ & 0.410 \\
\hline \multicolumn{5}{|l|}{ Extent of CD } \\
\hline Ileitis & $11 / 128$ & $117 / 128$ & $0.47(0.23-0.99)$ & 0.040 \\
\hline Colitis & $8 / 73$ & $65 / 73$ & $0.75(0.33-1.7)$ & 0.500 \\
\hline Ileocolitis & $23 / 114$ & $91 / 114$ & $2.42(1.24-4.71)$ & 0.007 \\
\hline \multicolumn{5}{|l|}{ Extent of UC } \\
\hline Proctitis & $5 / 38$ & $33 / 38$ & $1.34(0.47-3.79)$ & 0.580 \\
\hline Left sided & $7 / 94$ & $87 / 94$ & $0.56(0.23-1.39)$ & 0.210 \\
\hline Extensive & $15 / 121$ & $106 / 121$ & $1.43(0.64-3.19)$ & 0.390 \\
\hline Smoking & & & & 0.030 \\
\hline Never & $18 / 220$ & $202 / 220$ & & \\
\hline Smoker (current or previous) & $48 / 339$ & $291 / 339$ & $1.85(1.04-3.29)$ & \\
\hline Immunosuppression & & & & 0.140 \\
\hline No & $55 / 410$ & $355 / 410$ & $0.62(0.32-1.19)$ & \\
\hline Any & $12 / 138$ & $126 / 138$ & & \\
\hline
\end{tabular}

caused by immunosuppressives. This is supported by the lack of association between immunosuppressive agents and TB in this study.

We acknowledge that our inclusion criteria for the TB-positive group may not have been accurate. A history of TB treatment does not necessarily equate to $\mathrm{TB}$ infection; empiric therapy is often given without bacteriological confirmation. Misclassification bias may have resulted in falsely inflated numbers.

Our data establish a comparator for further study. We recommend active screening of IBD patients for $\mathrm{TB}$ at diagnosis, before commencing immunosuppressive therapy according to international guidelines. With the combination of endemic TB and emerging IBD, more data are needed to develop appropriate guidelines for the developing world.

\section{References}

1. World Health Organization (WHO). Global Tuberculosis Control 2009: Epidemiology, Strategy and Financing. WHO/HTM/TB/2009. Geneva: WHO, 2009.

2. Molodecky NA, Soon IS, Rabi DM, et al. Increasing incidence and prevalence of the inflammatory bowel diseases with time, based on a systemic review. Gastroenterology 2012;142(1):46-54. [http:// dx.doi.org/10.1053\%2Fj.gastro.2011.10.001]

3. Ahuja V, Tandon RK. Inflammatory bowel disease in the Asia-Pacific area: a comparison with developed countries and regional differences. J Dig Dis 2010;11(3):134-147. [http://dx.doi.org/10.1111\%2Fj.1751 2980.2010.00429.x]

4. Clark M, Colombel JF, Feagan BC, et al. American gastroenterological association consensu development conference on the use of biologics in the treatment of inflammatory bowel disease, June 21-23, 2006. Gastroenterology 2007;133(1):312-39. [http://dx.doi.org/10.1053\%2Fj. gastro.2007.05.006

5. D'Haens GR, Panaccione R, Higgins PD, et al. The London position statement of the World Congress of Gastroenterology on biological therapy for IBD with the European Crohn's and Colitis Organization when to start, when to stop, which drug to choose, and how to predict response? Am J Gastroentero 2011;106(2):199-221. [http://dx.doi.org/10.1038\%2Fajg.2010.392]

6. Bernstein CN, Fried M, Krabshuis JH, et al. World Gastroenterology Organization practice guidelines for the diagnosis and management of IBD in 2010. Inflamm Bowel Dis 2010;16(1):112-124.[http:// dx.doi.org/10.1002/ibd.21048

7. Toruner M, Loftus EV, Harmsen WS, et al. Risk factors for opportunistic infections in patients with inflammatory bowel disease. Gastroenterology 2008;134(4):929-936. [http://dx.doi.org/10.1053\%2Fj. gastro.2008.01.012]

8. Burger D, Travis S. Conventional medical management of inflammatory bowel disease Gastroenterology 2011;140(6):1827-1837. [http://dx.doi.org/10.1053\%2Fj.gastro.2011.02.045]

9. Zabana Y, Domenech E, San Roman AL, et al. Tuberculosis chemoprophylaxis requirements an safety in inflammatory bowel disease patients prior to anti-TNF therapy. Inflamm Bowel Dis 2008;14(10):1387-1391. [http://dx.doi.org/10.1002\%2Fibd.20496]

10. Mahomed H, Hawkridge T, Verver S, et al. Predictive factors for latent tuberculosis infection among adolescents in a high-burden area in South Africa. Int J Tuberc Lung Dis 2011;15(3):331-336.

11. Centers for Disease Control and Prevention. Instructions to Panel Physicians for Completing Chest X-ray and classification worksheet (DS-3024). http://en.wikipedia.org/wiki/Tuberculosis radiology (accessed 8 January 2012).

12. Loly C, Belaiche J, Louis E. Predictors of severe Crohn's disease. Scand J Gastroenterol 2008;43(8):948954. [http://dx.doi.org/10.1080\%2F00365520801957149]

13. Lin HH, Ezzati M, Murray M. Tobacco smoke, indoor air pollution and tuberculosis: a systematic review and meta-analysis. PloS Med 2007;4(1):e20. [http://dx.doi.org/10.1371\%2Fjournal. pmed.0040020]

14. Jick SS, Lieberman ES, Rahman MU, Choi HK. Glucocorticoid use, other associated factors and the risk of tuberculosis. Arthritis Rheum 2006;55(1):19-26. [http://dx.doi.org/10.1002\%2Fart.21705]

15. Lichtenstein GR, Feagan BG, Cohen RD, et al. Serious infections and mortality in association with therapies for Crohn's disease: TREAT registry. Clin Gastroenterol Hepatol 2006;4(5):621-630. [http:// dx.doi.org/10.1016\%2Fj.cgh.2006.03.002]

16. Keane J, Gershon S, Wise RP, et al. Tuberculosis associated with infliximab, a tumor necrosis factor alphaneutralizing agent. NEngl JMed 2001;345(15):1098-1104. [http://dx.doi.org/10.1056\%2FNEJMoa011110] 